\title{
Ion Composition of Airway Surface Liquid of Patients with Cystic Fibrosis as Compared with Normal and Disease-control Subjects
}

\author{
Michael R. Knowles, ${ }^{\star}$ Joseph M. Robinson," Robert E. Wood, ${ }^{\ddagger}$ Charles A. Pue, ${ }^{\star}$ William M. Mentz," Gilbert C. Wager," \\ John T. Gatzy, ${ }^{\S}$ and Richard C. Boucher* \\ *Cystic Fibrosis/Pulmonary Research and Treatment Center, School of Medicine, ${ }^{\ddagger}$ Division of Pulmonary Diseases, Department of \\ Pediatrics, and ${ }^{\S}$ Department of Pharmacology, The University of North Carolina at Chapel Hill, Chapel Hill, North Carolina 27599; \\ "Pulmonary Medicine, St. Vincent’s Medical Center, Jacksonville, Florida 32204; "Dover, New Hampshire 03820
}

\begin{abstract}
To test whether a major contribution of airways epithelial ion transport to lung defense reflects the regulation of airway surface liquid (ASL) ionic composition, we measured ASL composition using the filter paper technique. On nasal surfaces, the $\mathrm{Cl}^{-}$concentration $(\sim 125$ meq/liter $)$ was similar to plasma, but the $\mathrm{Na}^{+}$concentration $(\sim 110 \mathrm{meq} / \mathrm{liter})$ was below plasma, and $\mathrm{K}^{+}$concentration $(\sim 30 \mathrm{meq} / \mathrm{liter})$ above plasma. The resting ASL osmolarity $\left[2\left(\mathrm{Na}^{+}+\mathrm{K}^{+}\right) ; 277\right.$ meq/liter] approximated isotonicity. There were no detectable differences between cystic fibrosis (CF) and normal subjects. In the lower airways, the $\mathrm{Na}^{+}$concentrations were 80-85 meq/liter, $\mathrm{K}^{+}$levels $\sim 15 \mathrm{meq} / \mathrm{liter}$, and $\mathrm{Cl}^{-}$concentrations 75-80 meq/liter. Measurements of $\mathrm{Na}^{+}$activity with $\mathrm{Na}^{+}$-selective electrodes and osmolality with freezing point depression yielded values consistent with the monovalent cation measurements. Like the nasal surfaces, no differences in cations were detected between CF, normal, or chronic bronchitis subjects. The tracheobronchial ASL hypotonicity was hypothesized to reflect collection-induced gland secretion, a speculation consistent with observations in which induction of nasal gland secretion produced hypotonic secretions. We conclude that there are no significant differences in ASL ion concentrations between CF, normal, and chronic bronchitis subjects and, because ASL ion concentrations exceed values consistent with defensin activity, the failure of CF lung defense may reflect predominantly factors other than salt-dependent defensins. (J. Clin. Invest. 1997. 100:2588-2595.) Key words: airway surface liquid defensins - airway epithelia - filter paper - gland secretions • $\mathrm{CF}$ ion composition
\end{abstract}

\section{Introduction}

The surface of the conducting airways is covered by a liquid that contains mucin macromolecules, electrolytes, and water.

\footnotetext{
Address correspondence to Michael R. Knowles, Cystic Fibrosis/Pulmonary Research and Treatment Center, The University of North Carolina at Chapel Hill, CB\#7248, 7019 Thurston-Bowles Bldg., Chapel Hill, NC 27599-7248.

Received for publication 28 May 1997 and accepted in revised form 11 September 1997.
}

J. Clin. Invest.

(C) The American Society for Clinical Investigation, Inc. 0021-9738/97/11/2588/08 \$2.00

Volume 100, Number 10, November 1997, 2588-2595

http://www.jci.org
This airway surface liquid (ASL) ${ }^{1}$ is thought to be organized into two components: a mucus layer and a periciliary liquid layer (1). The interaction of cilia with ASL promotes continuous clearance of inhaled foreign materials from the lung, which is believed to be a key lung defense mechanism (2).

It is not yet clear how the ion transport properties of the cells lining the airway surface contribute to lung defense. Because ion and water transport are difficult to measure in vivo, regulation of epithelial ion and water transport across the conducting airways has largely been inferred from studies of freshly excised airway epithelia in vitro or cultured epithelial cells $(1,3)$. One view suggests that airway epithelial ion transport promotes effective mucociliary clearance by regulating both the volume and ionic composition of $\operatorname{ASL}(4,5)$. This view proposes that the failure of cystic fibrosis (CF) lung defense reflects, in part, accelerated volume absorption of an isotonic fluid from airway surfaces (6), impairing lung defense by slowing mucociliary clearance. In contrast, a view emphasizing the role for the ionic strength of ASL in lung defense has been proposed $(7,8)$. This view suggests that airway epithelia regulate the ionic composition but not the volume of $\operatorname{ASL}(7,8)$. A recent study reported a raised concentration of $\mathrm{Cl}^{-}$in nasal surface liquid of CF as compared with normal subjects, and proposed that the failed lung defense in $\mathrm{CF}$ reflected the inhibitory effect of raised $\mathrm{Cl}^{-}$concentrations on antibacterial factors in CF airways (9).

A key point discriminating between these two views of the relationship of ASL to airways defense is the ionic composition of ASL of both normal and CF subjects. In this study, we used carefully calibrated techniques to measure under basal conditions the ionic concentration of the ASL lining the nasal mucosa of normal individuals and subjects with CF. Because a major role for cystic fibrosis transmembrane conductance regulator (CFTR) in gland function has been inferred from in situ hybridization studies localizing CFTR in the lung to gland acini (10), we also tried to define the contribution of glandular secretion to ASL composition. Finally, we extended these measurements to the basal ASL ion concentrations in bronchi of normal subjects, noninfected CF patients, and disease control (chronic bronchitis) subjects.

\section{Methods}

\section{Subjects}

Normal. For nasal protocols, we studied a cohort of eight normal subjects (three female, five male; age $32.1 \pm 2.6 \mathrm{yr}$ ) with no history of

1. Abbreviations used in this paper: ALI, air-liquid interface; ASL, airway surface liquid; $\mathrm{CB}$, chronic bronchitis; $\mathrm{CF}$, cystic fibrosis; CFTR, cystic fibrosis transmembrane conductance regulator; $\mathrm{DDH}_{2} \mathrm{O}$, double-distilled, deionized $\mathrm{H}_{2} \mathrm{O}$. 
chronic rhinitis and no acute nasal symptoms for at least $2 \mathrm{wk}$. None took any chronic medication. For each protocol, subjects were studied on separate days. For bronchial surface liquid studies with filter papers and the $\mathrm{Na}^{+}$electrode, we studied 15 normal subjects (seven female, eight male; mean age $25.9 \pm 1.2 \mathrm{yr}$ ). These subjects exhibited no chronic respiratory symptoms and no acute respiratory illness for at least $2 \mathrm{wk}$; none took any chronic medication.

$C F$. Nasal protocols included nine CF patients (four female, five male; mean age $26.9 \pm 2.1 \mathrm{yr}$ ) with no acute nasal symptoms for at least 2 wk. None took chronic nasal medication. For each protocol, subjects were studied on separate days. For bronchial surface liquid, we analyzed filter paper samples from bronchoscopies in nine newly diagnosed $\mathrm{CF}$ patients (six female, three male; mean age $1.2 \pm 0.3 \mathrm{yr}$ ) who had no evidence of lower airway infection by quantitative bacteriology ( $<10,000 \mathrm{cfu}$ of pathogenic bacteria) in bronchial lavage. All $\mathrm{CF}$ patients had diagnostic sweat $\mathrm{Cl}^{-}$concentrations.

Chronic bronchitis. For the bronchial ASL measurements, we studied nine patients (six female, three male; mean age $38.3 \pm 2.8 \mathrm{yr}$ ) with a history of cigarette-induced chronic bronchitis, but no acute change in pulmonary symptoms for at least 1 mo. None were taking inhaled or systemic steroids or oral bronchodilators. Inhaled bronchodilators were held for at least $12 \mathrm{~h}$ before bronchoscopy.

\section{Filter paper studies}

Filter papers. Filter paper pledgets were cut from Whatman 541 hardened ashless paper (Clifton, NJ). Individual papers for the nasal studies were $\sim 4 \mathrm{~cm}$ in length and $5 \mathrm{~mm}$ in width. The papers were washed trebly in double-distilled, deionized water $\left(\mathrm{DDH}_{2} \mathrm{O}\right)$ and dried in an oven overnight and then stored. Papers were folded in half width-wise, and weighed on the day used (just before sampling). For sampling, the end of the paper was grasped in a hemostat and positioned as a "V" laterally under the inferior turbinate for $20 \mathrm{~s}$. For the adult bronchial studies, the filter papers were prepared in the same manner, but five papers $(\sim 2-3 \mathrm{~cm} \times 2-3 \mathrm{~mm})$ were loaded into biopsy forceps as previously described $(11,12)$. For the pediatric $\mathrm{CF}$ bronchial samples, three filter papers $(\sim 2 \mathrm{~cm} \times 1 \mathrm{~mm})$ were used.

Weighing filter paper samples. The first measurement of the weight of samples collected on filter papers was made $\sim 15 \mathrm{~s}$ after removal from the subject, and serial measurements were made over the next $90 \mathrm{~s}$ (model No. 27; Cahn Electronic Balance, Cerritos, CA). A regression line was fit from these points and extrapolated to time zero to determine an initial weight as previously described $(11,12)$. To estimate the accuracy of weighing filter paper samples, and control for evaporative water loss during transfer of the sample from the patient to the electronic balance, we added a known amount $(\sim 10 \mu \mathrm{l})$ of saline (150 meq/liter $\mathrm{NaCl})$ to the filter paper, and then transferred the sample to the balance as the nasal samples were handled. The loss of weight during transfer of the filter paper to the balance and the first weight measurement $(\sim 15 \mathrm{~s})$ was $3.1 \pm 1.2 \%(n=6)$. Back extrapolation from serial weighing projected an initial weight that was $99.5 \pm 1.2 \%$ of the volume added to the filter paper at time zero. We also measured the change in weight of filter paper exposed to the high humidity of the lower airways before the dry filter paper was touched to the airway surface. We noted a small weight gain over $30 \mathrm{~s}$ in the tracheal lumen $(0.18 \pm 0.06 \mathrm{mg} ; n=4 ; \sim 1 \%$ of the mean sample weight), and a similar increase $(0.29 \pm 0.01 \mathrm{mg} ; n=6)$ in the mouth over $30 \mathrm{~s}$ during slow exhalation through tightly pursed lips.

Extraction. After weighing, filter papers and aluminum-weighing pans were placed in acid-washed plastic vials. For ion analyses, $1 \mathrm{ml}$ of $\mathrm{DDH}_{2} \mathrm{O}$ was added to each specimen, and the vials were shaken on a gyrotory shaker (model G2, at $4^{\circ} \mathrm{C}$; Vendor, Edison, $\mathrm{NJ}$ ) for at least $24 \mathrm{~h}$. For analyses for albumin and osmolarity, filter papers were eluted overnight in $200 \mu \mathrm{l}$ of $\mathrm{DDH}_{2} \mathrm{O}$. For ion analyses, the solution in the vials was transferred to acid-washed volumetric tubes $(2 \mathrm{ml})$ and $0.5 \mathrm{ml}$ of $0.2 \mathrm{~N} \mathrm{HNO}_{3}$ was added to the vial. The paper was stirred and then "wrung out" with forceps to remove the liquid. This liquid was added to the volumetric tube. The maneuver was repeated and the extract was brought up to $2 \mathrm{ml}$ with $0.2 \mathrm{~N} \mathrm{HNO}_{3}$. We tested the efficiency of extraction from filter papers of ion solutions of known composition. Solutions (10 and $25 \mu \mathrm{l})$ with known composition $\left(\mathrm{Na}^{+}=145.9 \mathrm{mM}, \mathrm{Cl}^{-}=134.8, \mathrm{~K}^{+}=3.1 \mathrm{mM}\right)$ were applied to filter papers and the papers were carried through the extraction and ion analysis protocol. The extraction efficiency from five experiments with each volume $(10$ and $25 \mu \mathrm{l})$ was similar, and mean recovery of each ion exceeded $99 \%$ as compared with the concentration of ions pipetted directly into aluminum pans.

Ionic analysis. Chloride was measured with a digital chloridometer (model 442-5000; Labconco, Kansas City, MO) as previously described (13). To prepare for titration, $1 \mathrm{ml}$ of the 2-ml extract was added to a solution of $1 \mathrm{ml} \mathrm{DDH} \mathrm{H}_{2} \mathrm{O}, 2 \mathrm{ml}$ of Labconco acid reagent, $0.2 \mathrm{ml}$ of glacial acetic acid, and two drops of indicator. Standards of known $\mathrm{Cl}^{-}$concentration $(0,20,40,60,80,100,200,300,500,1,000$, and 2,000 $\mathrm{\mu eq} / \mathrm{liter})$ were prepared with the same reagent indicator solution. Values for blanks $\left(1 \mathrm{ml}\right.$ of $0.2 \mathrm{~N} \mathrm{HNO}_{3} ;<4 \%$ of the value for any specimen) were subtracted to yield final sample value. The standard curve for $\mathrm{Cl}^{-}$concentration was linear from 100 to 2,000 $\mu \mathrm{eq} / \mathrm{liter}$, and hyperbolic from 0 to $100 \mu \mathrm{eq} / \mathrm{liter}$. $\mathrm{Na}^{+}$and $\mathrm{K}^{+}$in the remaining $1 \mathrm{ml}$ of extract were measured with a flame photometer (model $51 \mathrm{ca}$; Perkin-Elmer Corp., Norwalk, CT) as previously described (13). Standard curves for $\mathrm{K}^{+}$were linear over a wide range of concentration ( 20 to $2,000 \mu \mathrm{eq} / \mathrm{liter}$ ), whereas the relationships for $\mathrm{Na}^{+}$were curvilinear ( 0 to $2,000 \mu \mathrm{eq} / \mathrm{liter}$ ). We estimate a limit of detection for $\mathrm{Cl}^{-}$and $\mathrm{K}^{+}$of $\sim 500$ and 20 neq, respectively. These limits correspond to $\sim 2.5 \mu \mathrm{l}$ of a $100 \mathrm{mM} \mathrm{NaCl}$ solution and $\sim 1 \mu \mathrm{l}$ of a solution with $25 \mathrm{meq} /$ liter $\mathrm{K}^{+}$. Accordingly, specimens $<3 \mu$ l (i.e., 3 $\mathrm{mg}$ ) were not analyzed. Because our analyses routinely underestimated the nominal $\mathrm{Na}^{+}$and $\mathrm{Cl}^{-}$concentrations of physiologic salt solutions (e.g., media, Ringer's solution) by an average of $6 \%$, we applied this correction to all specimens. The correction did not change the pattern of ion composition of airway liquid from any subject population, or comparisons among populations, but tended to bring estimated osmolarities for basal nasal specimens close to isosmolarity.

Protein and osmolarity analysis. Albumin was determined by radioimmunoassay (13), and osmolality was measured by freezing point depression (Osmette, model 2007; Precision Systems, Sudbury, MA), as previously described (13).

\section{Analysis of $\left[\mathrm{Na}^{+}\right]$in airway surface liquid with $\mathrm{Na}^{+}$-selective electrodes}

$\mathrm{Na}^{+}$-selective glass electrodes (\#MI-420; selectivity $\mathrm{Na}^{+}$over $\mathrm{K}^{+}$ 1000:1; Microelectrodes, Inc., Londonderry, NH) were used, coupled to a reference electrode (5.0 silk thread), and saturated with $100 \mathrm{mM}$ $\mathrm{KCl}$. The output $(\mathrm{mV})$ of the $\mathrm{Na}^{+}$electrode was determined in four $\mathrm{NaCl}$ solutions $(25.6,77,154$, and $256 \mathrm{mM})$. A standard curve was generated before each study, and repeated immediately after each study. A semilog plot yielded a mean slope of $53.0 \pm 0.9 \mathrm{mV}$ per decade change in $\mathrm{Na}^{+}$activity at $34^{\circ} \mathrm{C}$. Surface liquid $\left[\mathrm{Na}^{+}\right]$on airways was assayed in anesthetized dogs. After anesthesia with parenteral pentobarbital $(25 \mathrm{mg} / \mathrm{kg})$ and intubation with a shortened endotracheal tube, the $\mathrm{Na}^{+}$and reference electrodes (housed in a protective catheter) were passed transbronchoscopically into the lower airways and touched lightly to the distal tracheal surface until a stable measurement was obtained for 10-15 s at two to four different sites.

\section{Canine epithelial cell cultures}

To estimate the potential damage induced by placement of filter papers on epithelial surfaces, and potential artifacts generated by this effect and/or sampling of cellular ionic contents due to adherence of epithelial cells to the filter paper, a series of studies was performed in air-liquid interface (ALI) cultures. Dog tracheal cells were cultured to confluence on 24-mm Transwell Col supports, and exposed to an ALI to allow development of a well-differentiated phenotype (3-4 wk after seeding) $(14,15)$. The ALI epithelial preparations were equilibrated with lumenal media $(500 \mu \mathrm{l})$ containing (in meq/liter) $\mathrm{Na}^{+}=132, \mathrm{Cl}^{-}=120$, and $\mathrm{K}^{+}=5.8$, and measurements of transepithelial resistance $\left(R_{\mathrm{t}}\right)$ made (EVO-M; World Precision Instruments, 
Sarasota, FL), after which excess fluid was gently removed. $4 \mathrm{~h}$ later, ASL was sampled. Surface liquid was aspirated directly from some cultures using a micropipette for measurements of ion concentration. Surface liquid was sampled from other cultures with filter paper applied to the surface for $20 \mathrm{~s}$. Measurements of transepithelial resistance $\left(R_{\mathrm{t}}\right)$ were repeated after sampling by aspiration or filter paper.

\section{Human protocols}

Studies of solution recovery. For studies of the accuracy of the sampling and measurement techniques, Atrovent $(168 \mu \mathrm{g}$ in $150 \mathrm{mM}$ $\mathrm{NaCl}$ ) was applied topically (spray) to the nasal mucosa in each nostril to inhibit secretion $(16,17)$. After 30-60 min, Atrovent-pretreated nasal surfaces were sprayed under direct vision (six sprays; $0.25 \mathrm{ml}$ per spray) with saline $(150 \mathrm{mM} \mathrm{NaCl})$ in each nostril, and the mucosal surface liquid was sampled immediately with filter papers $(\sim 15-30 \mathrm{~s}$ later).

Baseline nasal ASL collections. Each nostril was completely occluded with a polyethylene plug to minimize evaporative water loss from nasal surfaces before sampling after defined times $(5,10,20$ $\min$ ) to determine the time required to reach steady-state equilibration of electrolytes. Because $10 \mathrm{~min}$ of occlusion was found to be required for equilibration of ASL (see Results), this time (10 min) was used for most protocols. To obtain samples of basal surface liquid, the plug was removed and filter paper was gently placed under direct vision on the nasal surface in a region that allowed contact with liquid on the inferior surface of the inferior turbinate and the floor. The filter paper was left in place for $20 \mathrm{~s}$ and then removed and weighed as described above.

Gland contribution to nasal ASL composition. The gland secretion was stimulated without adding a drug/vehicle directly to the nasal surfaces by occluding the nasal passages with plugs for $10 \mathrm{~min}$ and then having subjects chew hot chili peppers, a maneuver that has been shown to induce a glandular reflex secretion in the nasal mucosa, for $5 \mathrm{~min}$ (18). Surface liquid was sampled from nostrils after the chili pepper gustation.

Lower airway protocols. (a) Normal subjects and patients with chronic bronchitis: after topical anesthesia of the nose (viscous lidocaine, $2 \%$ ), the throat was anesthetized with topical lidocaine $(1 \%)$ with the patient in the Trendelenburg position. Normal subjects undergoing filter paper sampling received atropine ( $0.6 \mathrm{mg}$ I.M.; $n=$ $6)$ or no atropine $(n=5)$; there was no difference in volume (wt) or electrolyte composition of ASL samples obtained with or without atropine, and data were grouped for presentation. After parenteral sedation (meperidine, $25-150 \mathrm{mg}$; \pm midazolam, 2-10 mg), a fiberoptic bronchoscope was introduced into the lower airways, and pretared filter paper strips held by standard biopsy forceps housed in a protective catheter were placed transbronchoscopically onto the mucosal surface for $20 \mathrm{~s}$ as previously described $(11,12)$. The filter papers with sampled ASL were withdrawn into the catheter, removed from the broncoscope, and immediately weighed to determine volume of sample. Two to five filter paper samples were obtained from the mainstem and lobar bronchus, and one to two samples from distal trachea, of each subject, and samples were processed as described above. For studies with the $\mathrm{Na}^{+}$-selective electrode in normal subjects, topical anesthesia and sedation without atropine were performed as for filter paper studies. The $\mathrm{Na}^{+}$and reference electrodes were housed in a protective catheter and passed transbronchoscopically into the lower airways (as above), and held lightly against the airway surface of the mainstem or lobar bronchus until a stable measurement was obtained for 10-15 s at two to five different sites. (b) Cystic fibrosis: these patients were bronchoscoped shortly after the diagnosis of CF to define the infection status of the lower airways. The filter paper samples were obtained under a research protocol coupled to the clinically indicated bronchoscopy. After topical anesthesia of the nose (viscous lidocaine), the throat was anesthetized with topical lidocaine ( $2 \%$; $1 \mathrm{ml}$ ) with the patient in the Trendelenberg position. After parenteral sedation (meperidine, 1-2 mg/kg; midazolam, 0.005-0.015 mg/kg), pretared filter papers held by biopsy forceps housed in a protective catheter were placed onto the mucosal surface of the mainstem bronchus for $20 \mathrm{~s}$. The filter papers with ASL were withdrawn into the catheter, removed, and sample weighed and processed as described. After this maneuver, a $20-\mathrm{ml}$ bronchoalveolar lavage was performed for quantitative bacterial colony counts (19).

\section{Statistical analysis}

Nasal surface liquid electrolyte concentrations from each nostril of an individual, and multiple bronchial values for an individual, were averaged to give a value per subject for each electrolyte; study cohort mean values were derived from data per study subject. The difference between study cohorts was tested by nonpaired $t$ test. The response to gustatory submucosal gland stimulation within each study population was not normally distributed, and the change from baseline was tested by Wilcoxon sign rank (paired test). A $P$ value $<0.05$ was considered significant. The relationship between estimated osmolarity of bronchial surface liquid and size of sample was assessed by linear regression plot (Figure $\mathrm{P}^{\circledR}$; Biosoft, Cambridge, United Kingdom). All human protocols were approved by the UNC Human Rights Committee (IRB), and informed consent obtained. All animal protocols were approved by the International Animal Care and Use Committee.

\section{Results}

Controls for sampling, weighing, elution, and ion concentration measurements

Recovery of a defined electrolyte solution added to the nasal mucosa in vivo. Because the ion concentrations in nasal surface liquid are quite different from those of plasma (see below), we evaluated the accuracy of our technique by measuring the concentration of ions in a defined solution deposited on the nasal surface. After Atrovent pretreatment to inhibit gland secretion, nasal surfaces were sprayed with a $150-\mathrm{mM} \mathrm{NaCl}$ solution $(1.5 \mathrm{ml})$, using an atomizer spray. Ionic concentrations of surface liquid sampled immediately ( 15-30 s after nasal spray) approximated those of the saline spray (Fig. 1) for both normal and CF subjects. These data strongly suggest that the sampling and elution protocols accurately measure the composition of the solution on the nasal surface.

ASL sampled by aspiration or filter paper from the surface of cultured canine epithelia. The ALI epithelial cultures $(n=$ 6) were equilibrated with lumenal media $(500 \mu l)$ containing

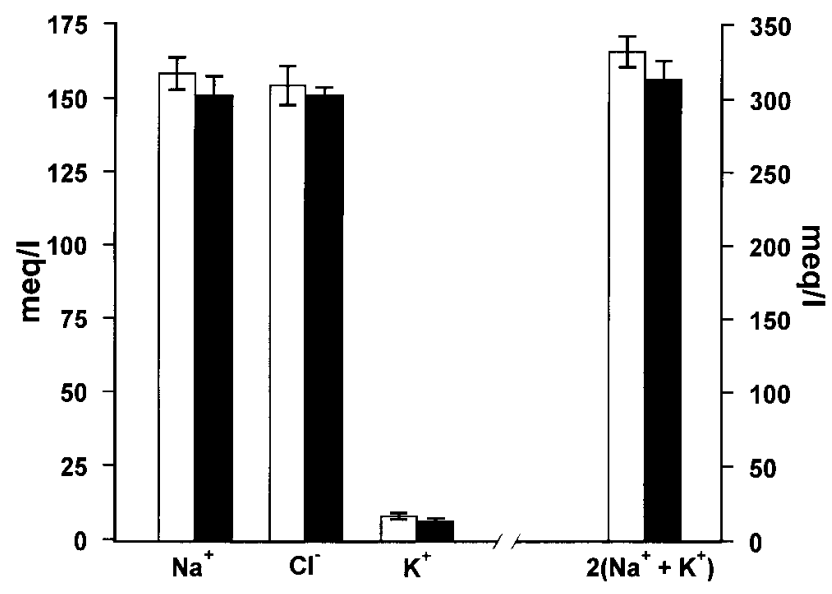

Figure 1. Ionic composition and estimated osmolarity of liquid on nasal surfaces of normal subjects ( $n=6$; open bars) and CF patients $(n=5$; solid bars) after nasal spray with isosmotic $\mathrm{NaCl}$ (150 meq/ liter). The estimated osmolarity [sum of cation concentrations, i.e., $\left.2\left(\mathrm{Na}^{+}+\mathrm{K}^{+}\right)\right]$is expressed in meq/liter. 
(in meq/liter) $\mathrm{Na}^{+}=132, \mathrm{Cl}^{-}=120$, and $\mathrm{K}^{+}=5.8$, and measurements of $V_{\mathrm{t}}$ and $R_{\mathrm{t}}$ made, following which excess fluid was gently aspirated. $4 \mathrm{~h}$ later, ASL was sampled. Liquid sampled by direct sampling techniques revealed concentrations (in meq/liter) of $\mathrm{Na}^{+}$equal to $124 \pm 3, \mathrm{Cl}^{-}$concentrations of $125 \pm 7$, and $\mathrm{K}^{+}$concentrations of $11.2 \pm 4.6$. Surface liquid recovered from the cultured epithelial cells with filter paper revealed concentrations (in meq/liter) of $\mathrm{Na}^{+}$of $125 \pm 11, \mathrm{Cl}^{-}$ $104 \pm 6, \mathrm{~K}^{+} 5.7 \pm 1.6$. The electrical resistance of cultures before and after direct and filter paper sampling were (in $\Omega . \mathrm{cm}^{2}$ ) pre $427 \pm 42$, post $439 \pm 32$; pre $426 \pm 25$, post $370 \pm 28$, respectively.

\section{Nasal ASL electrolyte concentrations}

Basal conditions. Preliminary experiments demonstrated that the variability of the electrolyte concentrations and the volume of liquid sampled from nasal surfaces increased until the occlusion time approached $10 \mathrm{~min}$; values at $20 \mathrm{~min}$ were no different in magnitude or variability than at $10 \mathrm{~min}$. At $10 \mathrm{~min}$, the weights collected by filter paper from normal $(18.0 \pm 2.2 \mathrm{mg})$ and CF subjects $(24.0 \pm 3.8 \mathrm{mg})$ were not different. The composition of ASL from normal subjects was characterized by a mean $\mathrm{Na}^{+}$concentration $\sim 25 \%$ below those of plasma, whereas the $\mathrm{K}^{+}$concentration was more than fivefold greater than plasma (Fig. 2). The concentration of $\mathrm{Cl}^{-}$was slightly higher than that of plasma and the calculated "anion gap," i.e., $\left(\mathrm{Na}^{+}+\mathrm{K}^{+}-\mathrm{Cl}^{-}\right)$, an estimate of the putative $\mathrm{HCO}_{3}{ }^{-}$concentration, was less $(\sim 8-12 \mathrm{meq} / \mathrm{liter})$ than the concentration of $\mathrm{HCO}_{3}{ }^{-}$in plasma. We multiplied the sum of cation concentrations $\left(\mathrm{Na}^{+}+\mathrm{K}^{+}\right)$by two to estimate osmolarity, and nasal surface liquid was close to isotonic (estimated $\sim 277 \mathrm{mOsm} /$ liter) with plasma ( $\sim 285 \mathrm{mOsm} / \mathrm{liter})$. Importantly, the mean ionic composition of samples from $\mathrm{CF}$ and normal subjects were not different for any ion.

Stimulation of nasal gland secretion. The ionic composition and sample weight of surface liquid for normal and CF subjects after stimulation of gland secretion with chili peppers were compared with paired basal values (Fig. 3). For normal subjects, the weight (volume) of secretions collected (20 s) increased approximately threefold after stimulation. Compared to the basal composition, there were small decreases in the

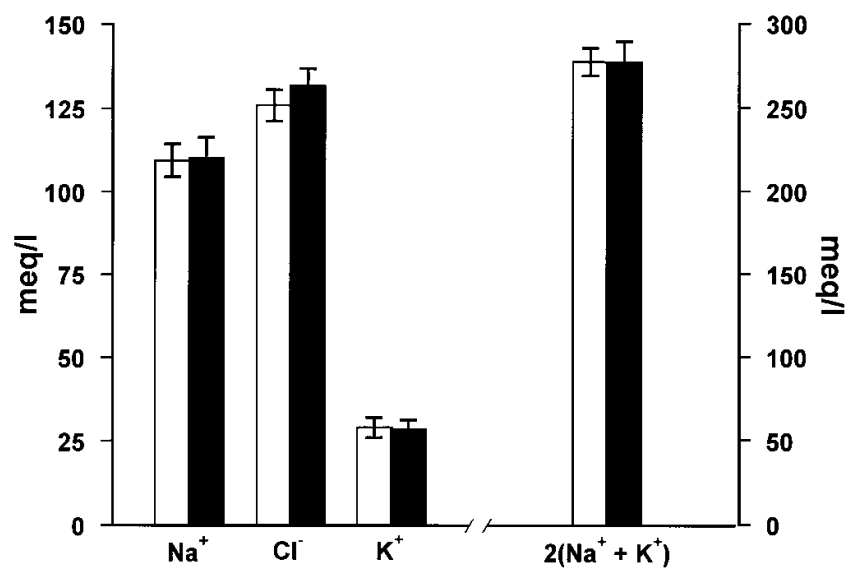

Figure 2. Ionic composition $\left(\mathrm{Na}^{+}, \mathrm{Cl}^{-}, \mathrm{K}^{+}\right)$and estimated osmolarity of nasal surface liquid (at baseline) in normal subjects ( $n=8$; open bars) and CF patients ( $n=8$; solid bars) after $10 \mathrm{~min}$ of nasal occlusion. The estimated osmolarity [sum of cation concentrations, i.e., $\left.2\left(\mathrm{Na}^{+}+\mathrm{K}^{+}\right)\right]$is expressed in $\mathrm{meq} / \mathrm{liter}$.
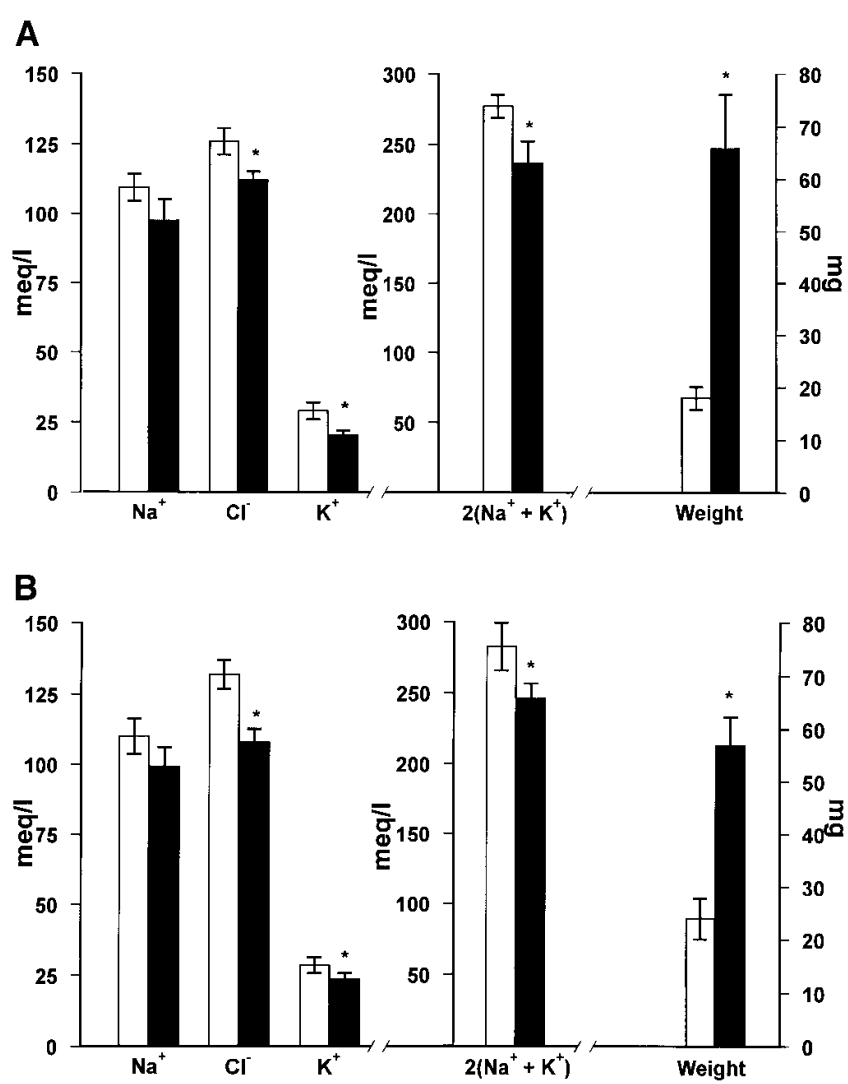

Figure 3. The volume (wt), ionic composition $\left(\mathrm{Na}^{+}, \mathrm{Cl}^{-}, \mathrm{K}^{+}\right)$and estimated osmolarity $\left[2\left(\mathrm{Na}^{+}+\mathrm{K}^{+}\right)\right]$of nasal surface liquid samples at baseline (open bars) and after gustatory stimulation of submucosal glands (solid bars) with chili peppers. (A) Normal subjects $(n=8)$ and $(B)$ CF patients $(n=8) . * P<0.05$, different from baseline.

concentration of $\mathrm{Na}^{+}, \mathrm{Cl}^{-}$, and $\mathrm{K}^{+}$, and a $\sim 40$ meq/liter decrease in estimated $\left[2\left(\mathrm{Na}^{+}+\mathrm{K}^{+}\right)\right]$osmolarity, suggesting that a hypotonic solution was secreted from glands.

The ionic composition of nasal surface liquid from CF subjects followed the same pattern as identified in normals (Fig. 3 $B)$. Wet weights rose more than twofold after chili pepper stimulation. Like nasal surface liquid from normals, there was a decrease in the concentration of $\mathrm{Na}^{+}, \mathrm{Cl}^{-}$, and $\mathrm{K}^{+}$, and $\mathrm{a} \sim 30$ $\mathrm{meq} /$ liter decrease in estimated osmolarity after stimulation.

\section{Lower airway surface liquid compositions}

Basal ASL values. The ionic composition of bronchial ASL from 11 normal subjects (compare Fig. $4 A$ with Fig. 2) differs substantially from the nasal cavity. The concentration of $\mathrm{Na}^{+}$ in bronchial surface liquids was $\sim 15 \%$ lower than in nasal surface liquid and $\sim 35 \%$ lower than plasma, and the concentration of $\mathrm{Cl}^{-}$in bronchial surface liquids was substantially lower than the concentration in either nasal surface liquids or plasma. Like nasal liquid, bronchial $\mathrm{K}^{+}$concentrations were greater than plasma (approximately three- to fourfold). The ion compositions of ASL from distal trachea $\left(\mathrm{Na}^{+} 80.0 \pm 5.2\right.$, $\mathrm{Cl}^{-} 88.4 \pm 9.8$, and $\mathrm{K}^{+} 21.7 \pm 3.9 \mathrm{meq} /$ liter) of five normal subjects were similar to those of bronchial ASL.

Differences among the ion compositions of bronchial and nasal surface liquids and plasma led us to check the estimates of bronchial surface liquid composition by alternative tech- 

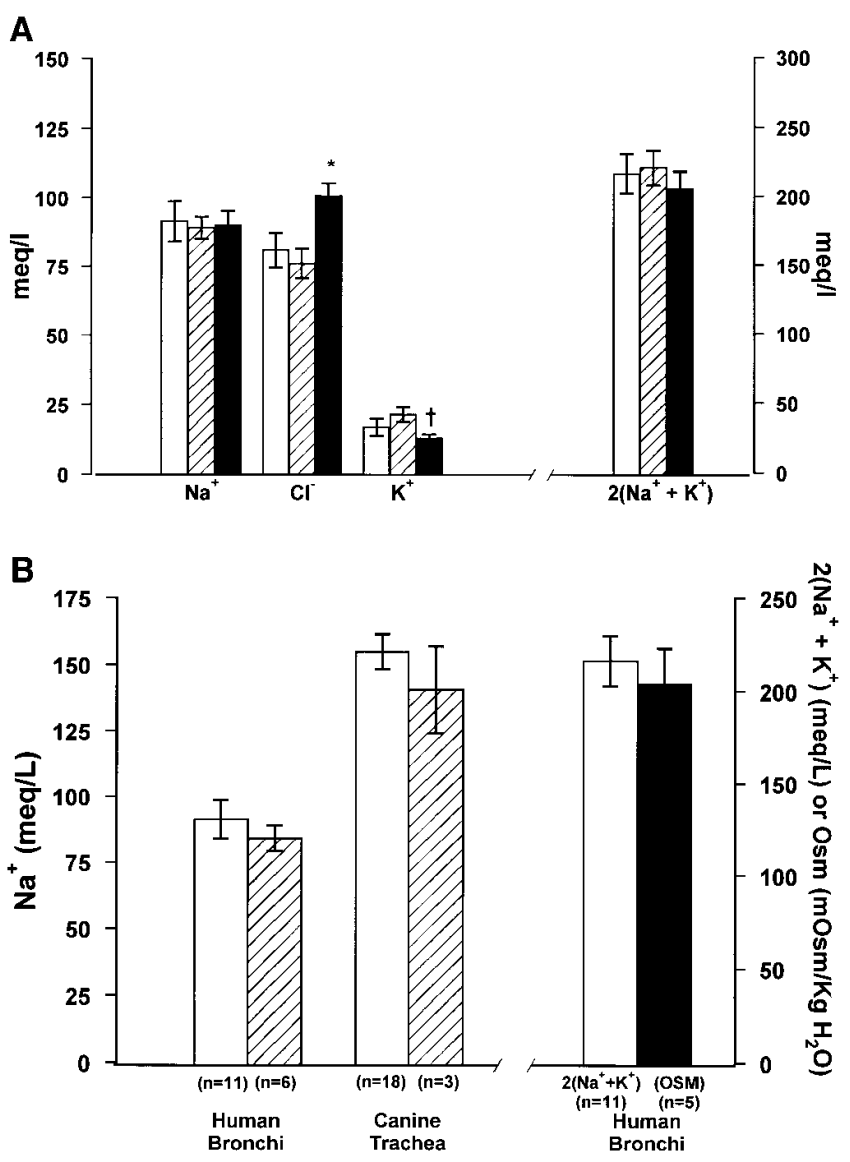

Figure 4. Ionic composition of surface liquid in lower airways. $(A)$ Ion composition $\left(\mathrm{Na}^{+}, \mathrm{Cl}^{-}, \mathrm{K}^{+}\right)$and estimated osmolarity $\left[2\left(\mathrm{Na}^{+}+\right.\right.$ $\left.K^{+}\right)$] of bronchial surface liquid in normal subjects $(n=11$; open bars), CF patients ( $n=9$; hatched bars), and patients with chronic bronchitis $(n=9$; solid bars $)$. $* P<0.05$, different from normal and $\mathrm{CF} ;{ }^{\dagger} P<0.05$, different from CF. $(B) \mathrm{Na}^{+}$concentration and osmolarity in airway surface liquid in normal human bronchi and canine trachea, and osmolarity in human bronchi, as determined by techniques of filter paper sampling (open bars), $\mathrm{Na}^{+}$electrode (hatched bars), and freezing point depression (solid bar). Canine tracheal filter paper data shown for comparison; previously published (13).

niques. The osmolality of surface liquid sampled by filter paper from five normal subjects, measured by freezing point depression, was found to be hyposmotic compared to plasma, and to be similar in magnitude to the estimate of $2\left(\mathrm{Na}^{+}+\mathrm{K}^{+}\right)$, suggesting that no molecules other than monovalent ions contribute to ASL osmolarity (Fig. $4 \mathrm{~B}$ ). Bronchial $\mathrm{Na}^{+}$concentrations were measured with $\mathrm{Na}^{+}$-selective electrodes immersed in ASL in vivo. We assessed the accuracy and sensitivity of the $\mathrm{Na}^{+}$electrode system in vivo by first making measurements in dog airways. The concentration of $\mathrm{Na}^{+}$measured with $\mathrm{Na}^{+}$-selective electrodes in canine tracheal surface liquid were comparable $(140.5 \pm 16.5 \mathrm{meq} / \mathrm{liter}, n=3)$ to previously reported values (Fig. 4 B) (13). Human bronchial ASL Na ${ }^{+}$ concentrations measured with $\mathrm{Na}^{+}$-selective electrodes in vivo approximate closely those estimated from samples on filter paper (Fig. $4 A$ ). The congruence of $\mathrm{Na}^{+}$concentrations measured by two independent techniques indicates that the filter paper protocol does not induce unique artifacts.
Finally, we measured albumin concentrations in normal human ASL to estimate the contribution of interstitial fluid that might enter surface liquid through leaks induced by filter paper sampling. The concentration of albumin in bronchial and tracheal surface liquid of six normal subjects $(73.2 \pm 27.0$ and $48.4 \pm 17.1 \mathrm{mg} / \mathrm{dl}$, respectively) was $\sim 60$ times less than that of plasma, suggesting that contamination of ASL by interstitial liquid that entered through albumin-permeant leaks was minimal.

We then compared the ionic composition of ASL collected from the lower airways of uninfected cystic fibrosis and uninfected chronic bronchitis patients with that collected from the normal volunteers (Fig. $4 A$ ). Like the ASL of normal subjects, liquids collected from these patients were characterized by low $\mathrm{Na}^{+}$, low $\mathrm{Cl}^{-}$, and raised $\mathrm{K}^{+}$concentrations compared to plasma. Importantly, we found ASL from each subject population was characterized by similar ion compositions, except for the $\sim 20 \%$ increase in $\mathrm{Cl}^{-}$in the noninfected chronic bronchitis subjects.

Relationship between volume of bronchial samples and osmolarity. To gain some insight into the contribution of collection-induced gland secretions to the hyposmotic ASL measured in the three study groups, we examined the relationship between the estimated osmolarity $\left[2\left(\mathrm{Na}^{+}+\mathrm{K}^{+}\right)\right]$and volume (wt) of samples collected for each group (Fig. 5). Bronchial surface liquid approaches isosmolarity in smaller samples (low wt) and becomes increasingly hyposmotic with increasing volume (wt) of samples.

\section{Discussion}

Despite intense interest in the characterization of ion transport by human airway epithelia over the last $15 \mathrm{yr}$, it is still not clear whether airway epithelia regulate volume and ionic composition of airway surface liquids or ionic composition alone $(1,3$, 6-9, 20, 21). Recent studies focusing on the relationship between ion composition of airway surface liquid and infectious pathogenesis of CF lung disease $(9,22)$ led us to measure and compare ion compositions of upper and lower ASL in normal subjects and subjects with airways disease.

Because the surface liquid layer is shallow, sampling and measurement of its composition are difficult, leading to a wide spectrum of reported values for human ASL (1). We therefore tested the accuracy of our sampling technique and compared our analytic protocols with independent techniques. Sampling with filter paper raises several questions. First, does the volume collected in the paper reflect the surface liquid volume/ unit area relationship in vivo? One approach to this question is to compare the volume on the airway surface in the region probed by the paper with the volume collected. Unfortunately, the depth of ASL on human airways is not known precisely and published values in mammalian proximal airways range from 1-120 $\mu \mathrm{m}$ (23-25). However, assuming a $25-\mu$ thick liquid layer, the volume of ASL in the vicinity of the filter paper (defined by its physical dimensions: $2-3 \mathrm{~mm} \times 20-30 \mathrm{~mm}$ ) should approximate 5-10 $\mu \mathrm{l}$. In the nose and in the lower airways, the volume collected in the basal state is approximately twofold higher than predicted $(\sim 10-20 \mu \mathrm{l})$. Possible explanations include epithelial damage and serum leak, "wicking" of surface liquid from outside of the estimated area sampled by the filter papers, and/or induction of reflex gland secretion. The very low albumin concentrations in airway surface liquids 

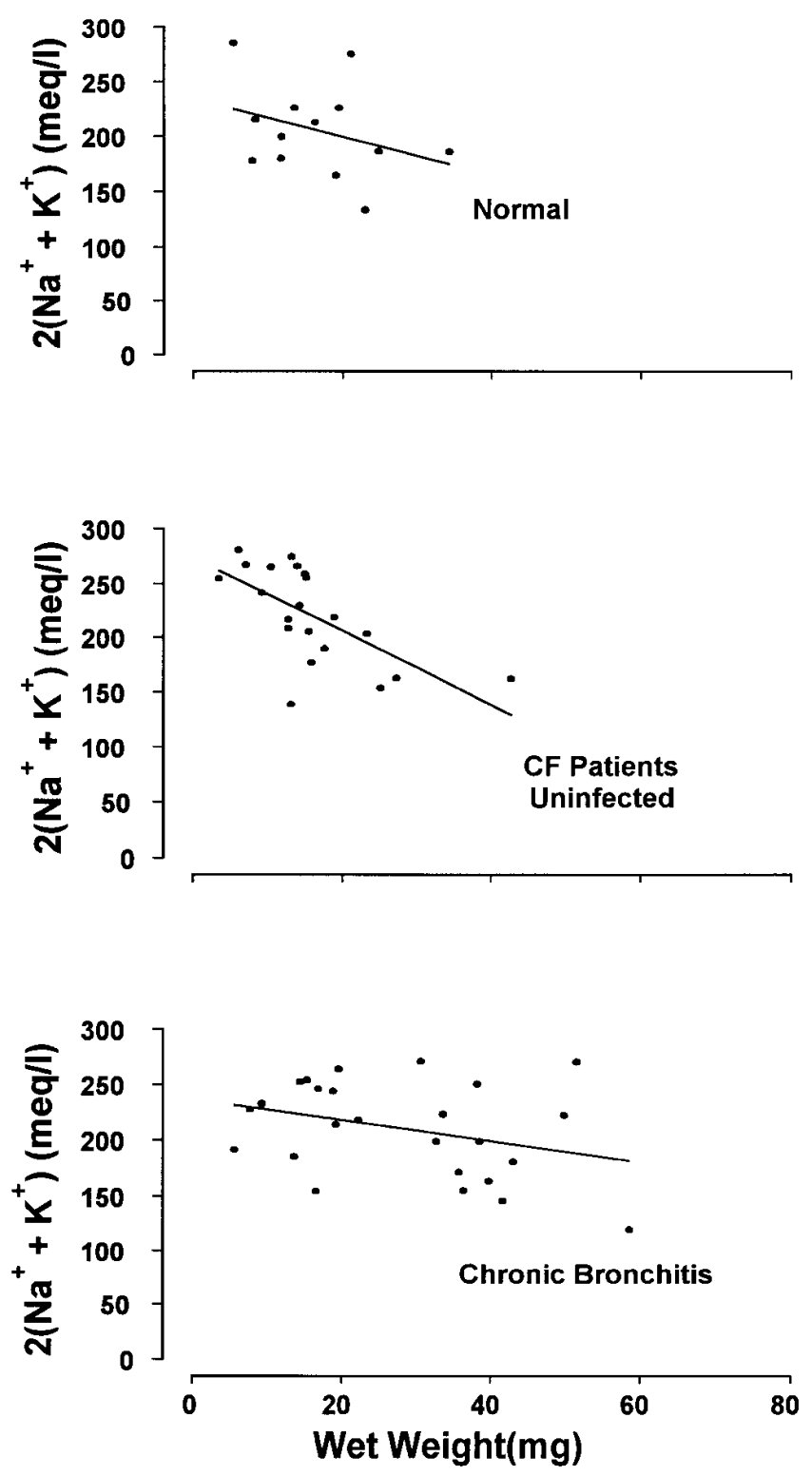

Figure 5. Relationship between the estimated osmolarity $\left[2\left(\mathrm{Na}^{+}+\right.\right.$ $\mathrm{K}^{+}$); $\left.\mathrm{meq} / \mathrm{l}\right]$ and volume (wt) of bronchial surface liquid sampled from normal subjects ( 11 subjects; 13 samples, $r=0.31$ ), patients with cystic fibrosis (nine subjects; 21 samples, $r=0.65$ ), and patients with chronic bronchitis (nine subjects; 28 samples, $r=0.41$ ).

and absence of detectable changes in epithelial resistance with filter paper sampling in vitro argue against the first explanation. The composition of gland secretions and their contribution to surface liquid volume in nose or lower airways of humans has not been previously described, so we cannot distinguish between or eliminate the other possibilities. However, our subsequent studies designed to measure ionic compositions under conditions that maximize the relative contribution of the glands to nasal surface liquid suggest that reflex gland secretion is probably induced in lower airways (see below).

Second, do the collection and elution protocols lead to an accurate measure of electrolytes? Because sampling from the surface of epithelial cell cultures did not raise the ASL concentration of $\mathrm{K}^{+}$, we conclude that raised concentration of $\mathrm{K}^{+}$in liquid sampled in vivo did not reflect cellular damage or adherent cells, consistent with previous analyses (13). We confirmed our previous experience with elution efficiency and analytic errors, showing that $>99 \%$ of known electrolyte added to filter paper is recovered (13). We have extended this experimental modeling further in the current study to define the limit of accuracy associated with sampling small volumes. The sensitivity of our analysis (3- $\mu$ l limit) was adequate to avoid excluding any samples due to insufficient sampled volume. Finally, the congruence of the concentrations of $\mathrm{Na}^{+}$and $\mathrm{Cl}^{-}$of the solutions sprayed onto the nasal surface with those measured within 1 min of deposition by filter paper sampling and analysis (Fig. 1) indicates that the entire procedure of sampling, weighing, and analyses is accurate and reliable.

We focused our studies on nasal surfaces so that our data could be compared with recent reports of $\mathrm{Cl}^{-}$concentrations in airway surface liquid from CF and normal subjects (9). After nasal occlusion, we found that there were time-dependent increases in volume collected and reductions in ionic concentrations. Approximately $10 \mathrm{~min}$ were required for equilibration after evaporative water loss was minimized with the nasal plugs. For both normal and $\mathrm{CF}$ subjects, $\mathrm{Na}^{+}$concentrations $(\sim 109 \mathrm{mM})$ were lower than those of plasma, $\mathrm{Cl}^{-}$concentrations $(\sim 125 \mathrm{mM})$ were similar to plasma, and $\mathrm{K}^{+}$concentrations $(\sim 30 \mathrm{mM})$ were higher than plasma. We found no significant difference between the ionic composition of liquid from $\mathrm{CF}$ and normal subjects. Subsequent to the original report of higher concentration of $\mathrm{Cl}^{-}$in $\mathrm{CF}$ surface liquid, Smith et al. have retracted the observations because the difference between CF and normal liquid could not be reproduced (26). Our study not only found no difference in $\mathrm{Na}^{+}$and $\mathrm{Cl}^{-}$concentrations between $\mathrm{CF}$ and normal nasal surface liquid, but our measured concentrations far exceed the values of $\mathrm{Na}^{+}$or $\mathrm{Cl}^{-}$(and tonicity) that are optimal for activity of salt-dependent defensins in the respiratory tract $(9,22)$.

We extended our studies to the lower airways, evaluating samples from the mainstem and second generation bronchi in normal healthy volunteers (mean age $26 \mathrm{yr}$ ). The ion composition of samples collected with filter paper differed from those taken from the nose in that $\mathrm{Na}^{+}, \mathrm{Cl}^{-}$, and $\mathrm{K}^{+}$concentrations were lower (Fig. $4 A$ ). Importantly, the sum of the cations suggested that the solution on bronchial surfaces is hyposmotic. A hyposmotic lower airway surface liquid is difficult to reconcile with water permeabilities reported for surface airway epithelia $(27,28)$. Consequently, we determined the osmolarity of filter paper samples and measured the concentration of $\mathrm{Na}^{+}$, the dominant cation, on the airway surface with $\mathrm{Na}^{+}$-selective electrodes. The concentration of $\mathrm{Na}^{+}$determined by these electrodes agreed with flame photometry of liquid sampled by filter paper, and the osmolarity measured by freezing point depression was comparable to the value estimated from $\mathrm{Na}^{+}$and $\mathrm{K}^{+}$concentrations (Fig. $4 \mathrm{~B}$ ). Thus, we conclude that the filter paper technique accurately measured the ionic composition of secretions on airway surfaces at the time of sampling.

We compared the normal data with those of bronchial surface liquid from nine infants with cystic fibrosis who were noninfected based on low bacterial counts in bronchoalveolar lavage (Fig. $4 A$ ). Concentrations of $\mathrm{Na}^{+}, \mathrm{Cl}^{-}$, and $\mathrm{K}^{+}$in $\mathrm{CF}$ ASL were not different from normal adult controls (Fig. $4 A$ ). Finally, we characterized electrolyte concentrations in surface liquid of adults with cigarette-induced chronic bronchitis without infection, a disease control. Again, electrolyte concentra- 
tions in these subjects did not differ from those of CF or normal subjects, except for a modest $(20 \%)$ increase in $\mathrm{Cl}^{-}$.

Our values for the ionic composition of CF bronchial ASL disagree with two published reports. Gilljam et al. (29) reported $\mathrm{K}^{+}$concentrations equal to plasma and $\mathrm{Cl}^{-}$concentrations higher than plasma in mucopurulent bronchial secretions (mean sample weights $=207 \pm 83 \mathrm{mg}$ ) aspirated by a dry catheter (29). Our data also describe CF surface liquid that is more hyposmotic than that recovered by Joris and colleagues (20). We do not know the reason for these discrepancies. However, Gilljam et al., like Smith et al. (9), reported $\mathrm{Cl}^{-}$concentrations that predict a hyperosmotic surface liquid, a composition that is not compatible with any known physiologic process in airway epithelia. The most likely explanation for a high $\mathrm{Cl}^{-}$concentration is evaporative water loss during sample collection and processing, or inadequate time for surface liquid humidification in vivo. The higher $\mathrm{Na}^{+}$and $\mathrm{Cl}^{-}$concentrations of bronchial samples from three CF patients (two intubated) reported by Joris et al. (20) may also reflect evaporative water loss, but we have no way to estimate the magnitude of these putative losses. Our data on CF ionic composition are similar to those reported by Wills et al. (5), the patient cohort in our study is relatively large, and this is the first uninfected CF cohort reported.

The volume of secretions recovered by the filter paper technique and apparent incompatibility of hypotonic bronchial surface liquid and the relatively high water permeability reported for superficial bronchial epithelia raised the possibility that the filter paper sampling technique induces reflex glandular secretion and that glands, as a function of their ductal ion transport activities, are the source of hypotonic solutions on airway surfaces. We attempted to separate the contribution of glands from superficial epithelium to the composition of liquid on airway surfaces by studying the effects of stimulated gland secretion. We sampled liquid from nasal surfaces because this surface is accessible to manipulation and all liquid on the superficial epithelia in this region is derived from the glands (i.e., there is no axial flow from more distal airways [1]). Reflex stimulation of nasal glands resulted in an increase in volume collected by filter papers from both $\mathrm{CF}$ and normal subjects (Fig. 3). Interestingly, the increase in volume was similar in normal and CF subjects, suggesting that non-CFTR $\mathrm{Cl}^{-}$transport pathways may be important in gland secretion in upper airways. Stimulation of gland secretion diluted the concentration of measured ions $\left(\mathrm{Na}^{+}, \mathrm{Cl}^{-}, \mathrm{K}^{+}\right)$, and there was a decrease (30-40 meq/liter) in the estimated osmolarity $\left[2\left(\mathrm{Na}^{+}+\right.\right.$ $\left.\mathrm{K}^{+}\right)$] of $\mathrm{CF}$ and normal nasal surface liquid after stimulation of submucosal glandular secretion (Fig. 3). Usually, hyposmotic gland secretion results from (hyperosmotic) $\mathrm{NaCl}$ absorption by ductal epithelium $(20,30)$. Although absorption by human submucosal gland ducts has not been measured directly, $\mathrm{Na}^{+}$ channels are expressed in the ducts of human normal and $\mathrm{CF}$ nasal glands (31).

Our conclusion that nasal gland secretions are hyposmotic led us to re-examine the estimated osmolarity of bronchial ASL. Fig. 5 displays the relationships between estimated osmolarity $\left(2\left[\mathrm{Na}^{+} \mathrm{K}^{+}\right]\right)$and volume of surface liquid samples from normal, $\mathrm{CF}$, and $\mathrm{CB}$ subjects. For each group, the smaller volume samples approach isotonicity, and as volume increased, osmolarity fell. We speculate that these relationships are the consequence of gland secretion induced by the collection technique. When this effect is minimized (e.g., volumes become smaller), ASL approximates isotonicity for all groups. Consequently, the low osmolarity in the bronchial surface liquid could reflect glandular secretion in this region.

In summary, we found no difference in ionic composition between surface liquid collected from nasal surfaces of CF and normal subjects under basal conditions. Nasal surface liquid is close to isosmotic. Stimulation of glands suggests that both $\mathrm{CF}$ and normal glands secrete a solution that is more hyposmotic than resting (basal) surface liquid. We suggest that submucosal gland ductal salt absorption lowers the osmolarity of solution secreted from gland acini. Our studies also did not reveal any difference among the ionic composition of airway surface liquids from bronchial regions of normal subjects, CF patients, or disease control patients. Human bronchial ASL tended to be hyposmotic relative to plasma, suggesting that the sampling technique in the lower airways disproportionately reflects glandular secretions rather than ambient airway surface liquids, or, less likely, that the high water permeability reported for excised airway epithelia is not relevant in vivo. Regardless of the explanation, the degree of hyposmolarity measured in either the nasal or bronchial surface is unlikely to activate saltsensitive defensin-like antimicrobial activities $(9,22)$. Finally, our studies point to the need for better collection techniques and reliable measurements of ionic composition in the bronchioles, the site at which CF disease is initiated. Although the conductive properties of bronchioles make it unlikely (32), it is possible that bronchiolar ASL is hypotonic in normal, but not $\mathrm{CF}$, and distal CF airways might be more susceptible to infection, if the hypothesis about salt-sensitive antimicrobial activity is valid. In addition, other important components of airway surface liquid (e.g., the water content, $\mathrm{pH}$ ) may be the key to the mystery of the early pathogenesis of $\mathrm{CF}$ airways infection.

Note added in proof: Since submission of this manuscript, we have become aware of a similar study, "Elemental content of airway surface liquid from infants with cystic fibrosis," Hull, J. et al. Am. J. Respir. Crit. Care Med. In press.

\section{Acknowledgments}

Thanks to Nina Church, Carla Foy, and Jon Winders for technical assistance, Peter Gilligan, Ph.D., for quantitative microbiology, and Lisa Brown for editorial assistance.

Support was provided by National Institutes of Health grants P01 32324 and RR000046, and CFF RDP 026.

\section{References}

1. Boucher, R.C. 1994. Human airway ion transport (part 1). Am. J. Respir. Crit. Care Med. 150:271-281.

2. Wanner, A., M. Salathe, and T.G. O'Riordan. 1996. Mucociliary clearance in the airways [State of the art]. Am. J. Respir. Crit. Care Med. 154:18681902.

3. Boucher, R.C. 1994. Human airway ion transport (part 2). Am. J. Respir. Crit. Care Med. 150:581-593.

4. App, E.M., J.G. Zayas, and M. King. 1993. Rheology of mucus and transepithelial potential difference: small airways versus trachea. Eur. Respir. J. 6 : $67-75$.

5. Wills, P.J., R.L. Hall, W. Chan, and P.J. Cole. 1997. Sodium chloride increases the ciliary transportability of cystic fibrosis and bronchiectasis sputum on the mucus-depleted bovine trachea. J. Clin. Invest. 99:9-13.

6. Jiang, C., W.E. Finkbeiner, J.H. Widdicombe, P.B. McCray, Jr., and S.S. Miller. 1993. Altered fluid transport across airway epithelium in cystic fibrosis. Science. 262:424-427.

7. Smith, J.J., P.H. Karp, and M.J. Welsh. 1994. Defective fluid transport by cystic fibrosis airway epithelia. J. Clin. Invest. 93:1307-1311.

8. Quinton, P.M. 1994. Viscosity versus composition in airway pathology [editorial]. Am. J. Respir. Crit. Care Med. 149:6-7. 
9. Smith, J.J., S.M. Travis, E.P. Greenberg, and M.J. Welsh. 1996. Cystic fibrosis airway epithelia fail to kill bacteria because of abnormal airway surface fluid. Cell. 85:1-20.

10. Engelhardt, J.F., J.R. Yankaskas, S.A. Ernst, Y. Yang, C.R. Marino, R.C. Boucher, J.A. Cohn, and J.M. Wilson. 1992. Submucosal glands are the predominant site of CFTR expression in human bronchus. Nat. Genet. 2:240-247.

11. Knowles, M.R., N.L. Church, W.E. Waltner, J.T. Gatzy, and R.C. Boucher. 1992. Amiloride in cystic fibrosis: safety, pharmacokinetics, and efficacy in the treatment of pulmonary disease. In Amiloride and its Analogs: Unique Cation Transport Inhibitors. E.J. Cragoe, Jr., T.R. Kleyman, and L. Simchowitz, editors. VCH Publishers, Inc. New York. 301-316.

12. Noone, P.G., J.A. Regnis, X. Liu, K.L.R. Brouwer, M. Robinson, L.J. Edwards, and M.R. Knowles. 1997. Airway deposition and clearance, and systemic pharmacokinetics of amiloride following aerosolization with an ultrasonic nebulizer to normal airways. Chest. 112:1283-1290.

13. Boucher, R.C., M.J. Stutts, P.A. Bromberg, and J.T. Gatzy. 1981. Regional differences in airway surface liquid composition. J. Appl. Physiol. 50: 613-620.

14. Gray, T.E., K. Guzman, C.W. Davis, L.H. Abdullah, and P. Nettesheim. 1996. Mucociliary differentiation of serially passaged normal human tracheobronchial epithelial cells. Am. J. Respir. Cell Mol. Biol. 14:104-112.

15. Matsui, H., L.G. Johnson, S.H. Randell, and R.C. Boucher. 1997. Loss of binding and entry of liposome-DNA complexes decreases transfection efficiency in differentiated airway epithelial cells. J. Biol. Chem. 272:1117-1126.

16. Wagenmann, M., F.M. Baroody, R. Jankowski, J.C. Nadal, M. RoeckerCooper, C.C. Wood, and R.M. Naclerio. 1994. Onset and duration of inhibition of ipratropium bromide nasal spray on methacholine-induced nasal secretions. Clin. Exp. Allergy. 24:288-290.

17. Baroody, F.M., A.M. Majchel, M.M. Roecker, P.J. Roszko, E.C. Zegarelli, C.C. Wood, and R.M. Naclerio. 1992. Ipratropium bromide (Atrovent nasal spray) reduces the nasal response to methacholine. J. Allergy Clin. Immunol. 89:1065-1075.

18. Raphael, G.O., M.H. Raphael, and M.A. Kaliner. 1989. Gustatory rhinitis: a syndrome of food-induced rhinorrhea. J. Allergy Clin. Immunol. 83:110-115.

19. Gilligan, P.H. 1991. Microbiology of airway disease in patients with cystic fibrosis. Clin. Microbiol. Rev. 4:35-51.
20. Joris, L., I. Dab, and P.M. Quinton. 1993. Elemental composition of human airway surface liquid in healthy and diseased airways. Am. Rev. Respir. Dis. 148:1633-1637.

21. Smith, J.J., and M.J. Welsh. 1993. Fluid and electrolyte transport by cultured human airway epithelia. J. Clin. Invest. 91:1590-1597.

22. Goldman, M.J., G.M. Anderson, E.D. Stolzenberg, U.P. Kari, M Zasloff, and J.M. Wilson. 1997. Human beta-defensin-1 is a salt-sensitive antibiotic that is inactivated in cystic fibrosis. Cell. 88:553-560.

23. Yager, D., T. Cloutier, H. Feldman, J. Bastacky, J.M. Drazen, and R.D. Kamm. 1994. Airway surface liquid thickness as a function of lung volume in small airways of the guinea pig. J. Appl. Physiol. 77:2333-2340.

24. Rahmoune, H., and K.L. Shephard. 1995. State of airway surface liquid on guinea pig trachea. J. Appl. Physiol. 78:2020-2024.

25. Widdicombe, J. 1997. Airway and alveolar permeability and surface liquid thickness: theory. J. Appl. Physiol. 82:3-12.

26. Smith, J.J., S.M. Travis, E.P. Greenberg, and M.J. Welsh. 1996. Erratum. Cell. 87.

27. Folkesson, H.G., M.A. Matthay, A. Frigeri, and A.S. Verkman. 1996. Transepithelial water permeability in microperfused distal airways. Evidence for channel-mediated water transport. J. Clin. Invest. 97:664-671.

28. Willumsen, N.J., C.W. Davis, and R.C. Boucher. 1994. Selective response of human airway epithelia to luminal but not serosal solution hypertonicity: possible role for proximal airway epithelia as an osmolality transducer. $J$. Clin. Invest. 94:779-787.

29. Gilljam, H., A. Ellin, and B. Strandvik. 1989. Increased bronchial chloride concentration in cystic fibrosis. Scand. J. Clin. Lab. Invest. 49:121-124.

30. Quinton, P.M., and M.M. Reddy. 1993. The sweat gland. In Cystic Fibrosis. P.B. Davis, editor. Marcel Dekker, Inc. New York. 137-159.

31. Burch, L., C. Talbot, M.R. Knowles, C. Canessa, B. Rossier, and R.C. Boucher. 1995. Relative expression of the human epithelial $\mathrm{Na}^{+}$channel $(\mathrm{ENaC})$ sub-units in normal and cystic fibrosis airways. Am. J. Physiol. 269: C511-C518.

32. Ballard, S.T., S.M. Schepens, J.C. Falcone, G.A. Meininger, and A.E. Taylor. 1992. Regional bioelectric properties of porcine airway epithelium. $J$. Appl. Physiol. 73:2021-2027. 